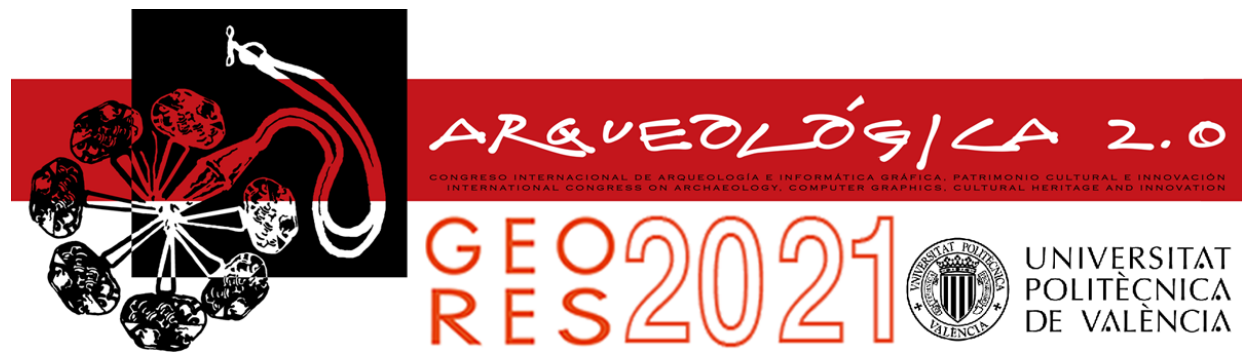

Proceedings of the joint international event $9^{\text {th }}$ ARQUEOLÓGICA

$2.0 \& 3^{\text {rd }}$ GEORES

Valencia (Spain).

26-28 April 2021

\title{
RESTORATION, REPRESENTATION, PROJECT: A DIALOGUE-LIKE APPROACH FOR THE COMPSA PALIMPSEST
}

\author{
Bianca Gioia Marino*, Raffaele Catuogno, Rossella Marena \\ DiARC Department of Architecture, University of Studies Federico II, Via Toledo 402, 80134 Naples, Italy. bianca.marino@unina.it; \\ raffaele.catuogno@unina.it; rossellamarena@gmail.com
}

\begin{abstract}
:
Compsa is the name of the ancient town of Conza della Campania, situated on a hill in the oriental part of Irpinia, Italy. The hill dominates the valley of the Ofanto River, on the border between Campania and Basilicata, in a high seismic risk area. After the 1980 earthquake, which almost completely destroyed the town, it was re-built in a new site in the valley. The ruins of the old town have been protected since 2004 by the establishment of the Archaeological and Historical Park, which has left intact the surviving urban fabric. The destruction of Conza Cathedral has brought out the remains of the Samnite, Roman and medieval Compsa. The discovered structures, as documented by important archaeological studies, testify to one of the most stratified settlements in Irpinia. An extensive study over the entire urban area founded on the dialogue between the examples of the restoration project and the potential to represent it through innovative, instrumental researchprojects has revealed not only unedited historical data which have enriched our knowledge as regards the site, but also significant traces to elaborate on the proposed project so as to re-evaluate such a unique archaeological park. The extreme complexity of the theme, which involves the urban and panoramic dimensions as well as the architectural one includes also the need for the re-evaluation of the archaeological park and the extraordinary co-presence of ancient evidence where the remains of the town are made up of rubble.
\end{abstract}

Keywords: Compsa, archaeological park, restoration, cultural heritage, documentation

\section{Registering the architectural reality of the "unexpected"}

In the understanding of reality, Salvatore Veca refers to the "unexpected" as an element and a willingness to accept dimensions without dividing the field of knowledge. What the scholar then emphasises with regard to the horizons of reading things seems to be the set of 'equipment' of method and approach with which the project to reuse and preserve an urban area destroyed by the earthquake was approached.

The case in question is the present-day Historical Archaeological Park in Compsa, the name of the ancient site of Conza della Campania, in Irpinia, Italy, situated on a hill that dominates the valley of the Ofanto River, in an extraordinary high-ground position (Fig. 1). After it had been almost completely destroyed following the earthquake and with the re-building/building of the new site in the valley, the ruins of the old town have been looked after through the setting-up of the Archaeological Park in 2004. Nevertheless, at the same time, the urban texture as well as the surviving buildings have been left intact. By demolishing and evacuating the parts which had collapsed, the remains of Compsa came to the fore. This was the ancient Sannite and Roman town which through the centuries had stratified the place until the destructive, catastrophic 1980 event. This study project, which involved the restoration disciplines along with the possibility for the development of a degree thesis, has experimented with an approach which aimed at cultivating, as regards the site, "una certa umiltà nell'ascolto [...] un buon grado di attenzione nei confronti di altre fisionomie, di altre voci, di altre grammatiche» (Veca, 2017), while trying to gather together all those things that the site could suggest on searching for solutions regarding its reasons for existing and being. Thus this was a reference point for the inhabitants, but not only, whose aim was to re-evaluate the archaeological park with its problems and its critical fruition elements. Therefore this was a multi-level research-project, which involved on an archaeological scale, urban lacunae and contextual and natural particularities which, even today, interact with the dimension of the ruins which are found throughout the entire area. The bottom line choice was thus a reception one which, while it never lost sight of the urban background which was still visible and could be traced back to the remains of an interrupted daily history, nonetheless it was sensitive to the archaeological strata and the material entities of the dismantled forms of architecture as well as to what had survived. With the aim of re-evaluating the Archaeological Park and following on from the methodology of the restoration project, a conscious and representative plan was set out. However 
this was not only limited to the archaeological evidence, and this is thanks to the campaigns which have been carried out and those which are still up and running.

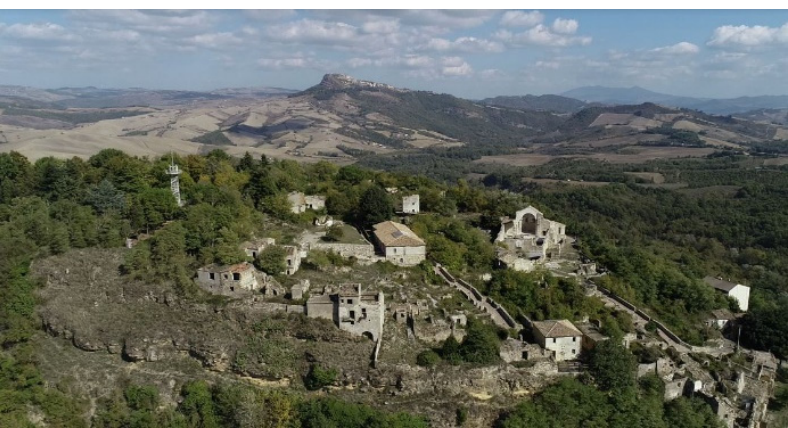

Figure 1: Aerial view of the Compsa Hill, video photogram by the Architect Marco Facchini, October 2019.

\section{The discovery of Compsa: the arrangement and the progression of the archaeological remains}

Immediately after the earthquake, the archaeological exploration carried out by Werner Johannowsky, led to one of the major research projects in Irpinia. Its aim was to be of immense relevance regarding the knowledge of the Sannite, Roman and medieval town (Johannowsky, 1982; Rea, 1982). A profitable season of studies started, even before, in the '70s, by G. C. Pescatori, G. Bailo Modesti and O. Onorato, whose studies set the basis for the knowledge of the archaic culture of the valley of Ofanto (Colucci Pescatori, 1988).

The area of the ancient city shows how carefully it had been chosen. The site occupies, indeed, a group of two hills, from which the entire valley is dominated. At least initially the coming of Romanization took over the preexisting Sannite structure where the original population had remained. This area was endowed with its own political and religious order, as well as its own usages and customs. Also the urban arrangement is a witness to such a stratification. It became a politically functioning administrative centre in the ancient Conza «coesistono, giustapposte al vecchio assetto topografico e sociale che ha resistito fino ai processi di municipalizzazione posteriori alla fine della guerra sociale e fino al I secolo, tutti quegli edifici pubblici che rappresentano le funzionalità della città romana: il foro, l'anfiteatro e le terme» (Di Giovanni, 2015).

In the urban texture, which even up to 1980 seemed to be based on the Roman one, it is possible to identify a plot of various axes which define the insulae. At least three decumans can be hypothesized which cross the city from east to west and two cardines, along the lines indicating the maximum incline of the hill (Fig. 2). The urban plan, which follows a terraced set of rules, adapts itself to the slope in the hill, with modest gains in height towards the south-east. On the plateau of the 'arce', the highest part of the hill, there is the amphitheatre, on the median terrace instead, there is the forum, while the thermal baths are in the lower part.

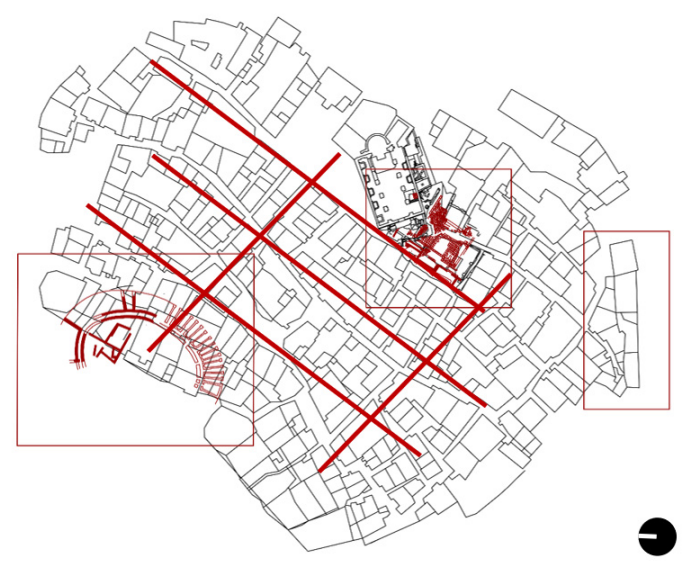

Figure 2: Conza della Campania (Compsa), plan of the modern city.

\subsection{Reading the historical layers. The archaeological flowerings in the urban context}

On the structure of the Thermal Baths, situated at the southern end of the park, is located one of the few building complexes which have survived the 1980 earthquake (Fig. 3). This one, in particular, presents a complex building stratification which encompasses internally mural structures, with a opus caementicium nucleus and an external-facing in opus latericium belonging to a thermal building which can be dated back to the $2^{\text {nd }}$ century A.D. The sac foundations of this walled structure seem to indicate the probable course of the city's mural defences which was firstly Irpinian and then Roman. They were probably demolished in the late-medieval period (Johannowsky, 1994). The facade is marked by successive adaptations as well as elements belonging to ancient manufactures (Fig. 4).

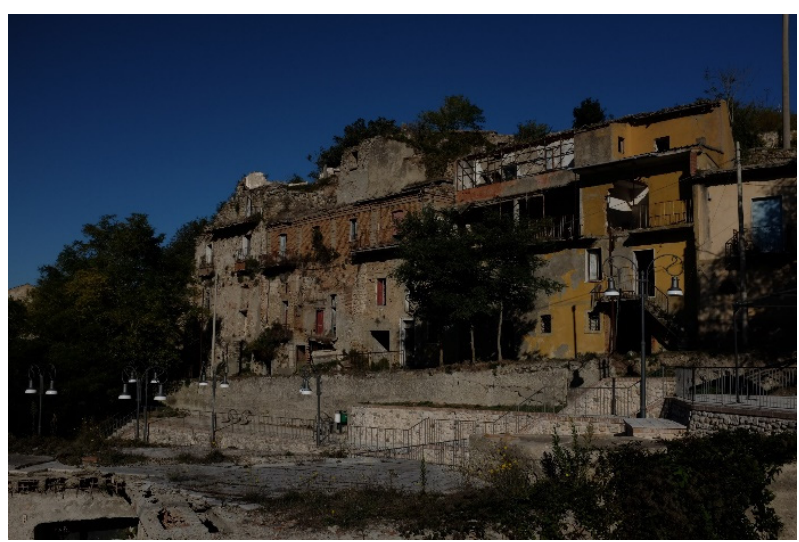

Figure 3: View of the building complex of the Thermal Baths ( $R$. Marena, October 2019).

The area corresponding to the Roman Forum, before 1980 , was completely taken up by private houses and its presence and positioning had already been set apart in the 1930s by Italo Sgobbo. A part of the podium of a temple, belonging to the northern side of the forum, and part of the calcareous canal set in front of it were, in fact, visible in a basement in a modern building. Besides part of the quadrangular slab pavement of the forum area in its median part, still in situ, was seen and used as a roadbed (Sgobbo, 1938). From the end of the ' 90 's systematic excavations, carried out by the Archaeological 
Superintendent of Salerno and Avellino, have investigated in various phases, the remaining part of the forum, giving back completely, at least for what still remains of it, the public monument in its planimetric development (Fig. 5).

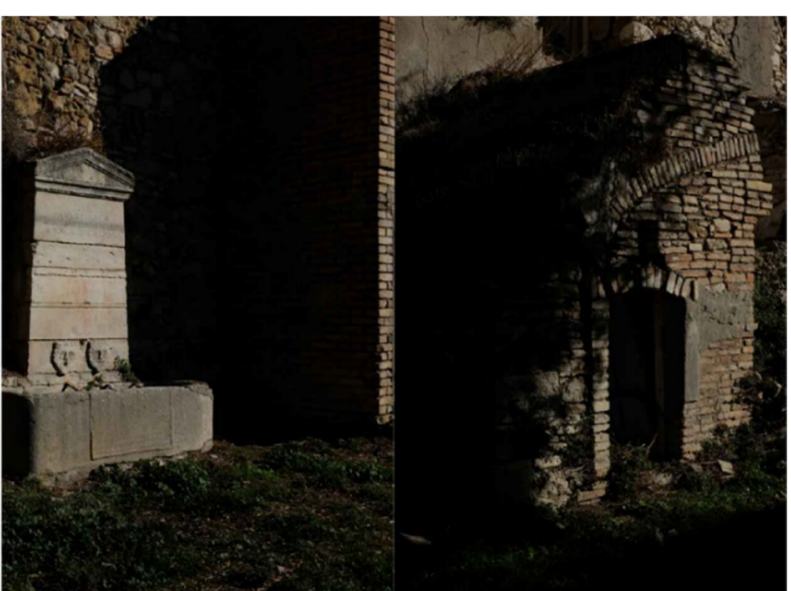

Figure 4: The Thermal Baths Complex. A particular of the stone facing and a detail of the sarcophagus in calcareous stone from the 4th century (R. Marena, October 2019).

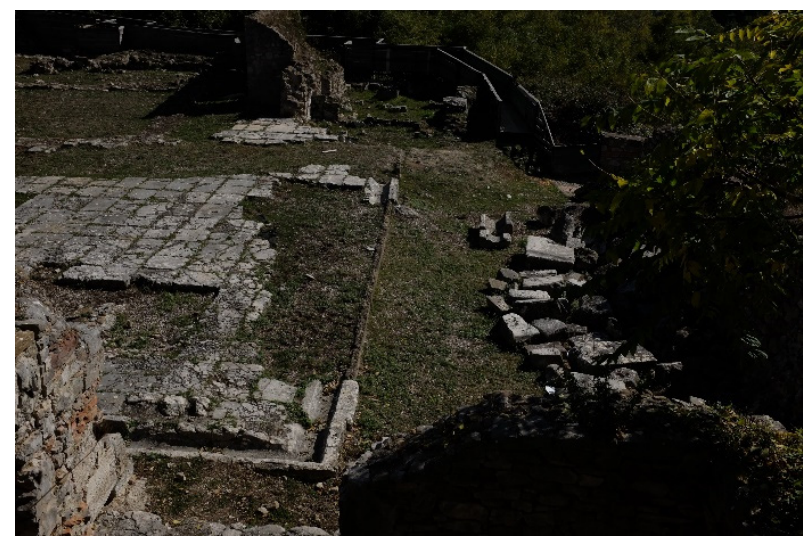

Figure 5: View of the Forum area (R. Marena, October 2019).

The cathedral was inserted in the Forum square from the Roman period, on a more elevated position with respect to the height of the ancient plan following an orientation that is different to it. The shots taken by drones have highlighted the wide rotation compared to the urban arrangement, placing itself outside the axis as regards the forum one and the rest of the installation which instead follows the orientation of the city (Fig. 6). It is not possible to date its foundation precisely. It definitely came after the Byzantine victory in 555 A.D. which led to a significant reorganization of the forum area and the re-use of a part of its structures as a cemetery. It was quoted for the first time in Concilium Romanum del 743. Many scholars are inclined to date the first cathedral to the 6 th or 7 th centuries.

Of the original structure, completely destroyed by the earthquake of 990 , some traces remain in the crypt. In its perimeter is preserved the layout of the right apse (Fig. 7 ), consisting of an irregular stone facing and an arch in opus vittatum formed by a succession of bricks and stones. Moreover, a frescoed, datable between the 12th and 13th centuries, is visible at its base. The covering of the crypt with cross vaults, uses supports obtained from the recovery of architectural elements of the previous construction. The interior is also characterized by the presence of classical elements of recovery such as bases and shafts of columns and epigraphs (Fig. 8).

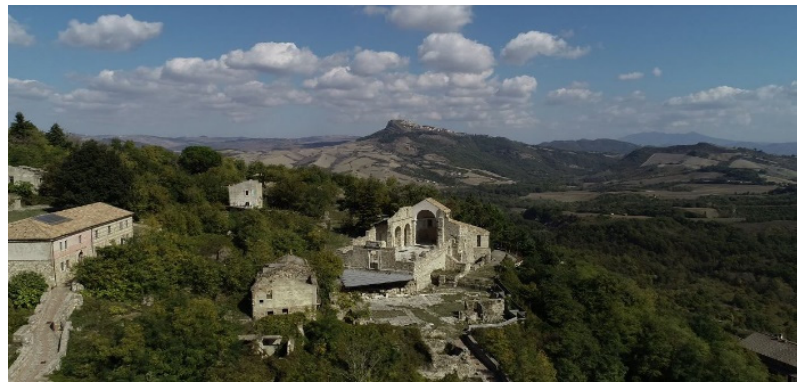

Figure 6: An aerial view of the forum area and the cathedral, photogram from a video by the Architect Marco Facchini, October 2019
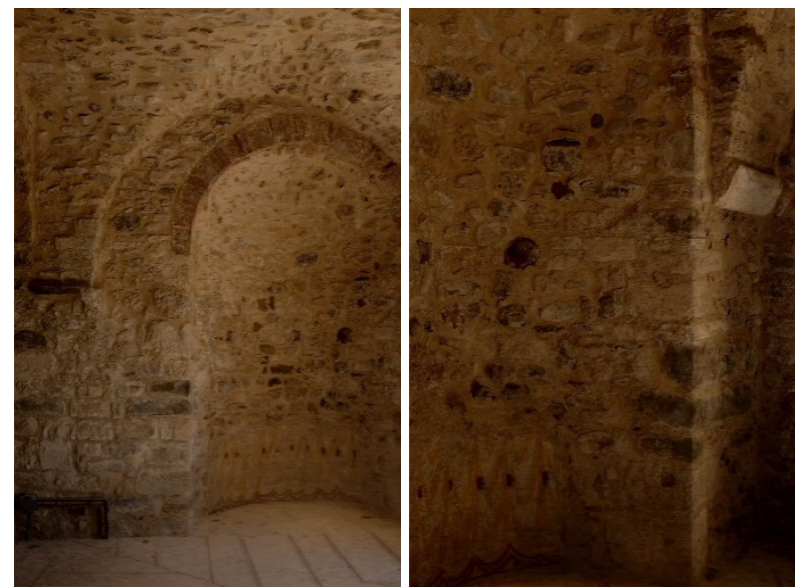

Figure 7: Crypt. The affrescoed at the base of the apse ( $R$. Marena, October 2019).

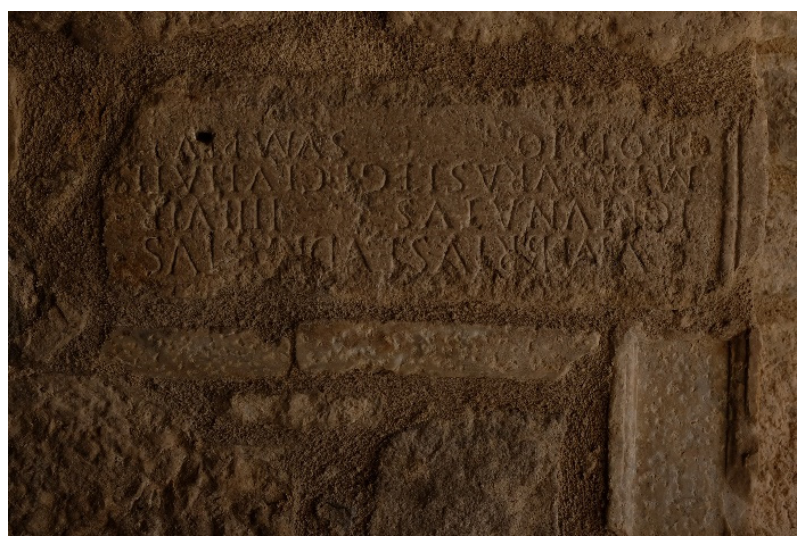

Figure 8: A particular of the epigraph found in the right-sided pillar of the arch of the crypt (R. Marena, October 2019).

The architectural layout of the cathedral, which is still visible, goes back to its last reconstruction in 1736 and, although it has inherited some features of medieval construction, is characterized by its recourse to an 18th century style, evident in the internal re-working and stucco-work in the central nave and in the new chapels in the side aisles (Fig. 9). The collapse caused by the 1980 earthquake have brought to light some pre-existing structures (in the south-west corner masonry structures from the Roman period), as well as the levels of the 
original floor and various tombstone-like elements sculpted in the $12^{\text {th }}$ century. A rich stratification, evidence of the continuous reconstructions on-site and the reuse of materials coming from the ancient constructions.

In the upper part of the town (Fig. 10), in the area used as a garden since the beginning of the 1900s, there was the Castle of the Gastaldi family and the Counts of Conza dating back to the $7^{\text {th }}$ century (Gargano, 1935; Acocella, 1927-1928). The remains, which were still visible in the 1950s, were completely demolished in 1957 to give way to the levelling work which was carried out, at that time, so that a football pitch could be built. In 1951, in the same area, during the building work on the water reservoir which was to be used by the town, further remains of an evidently medieval building were discovered and cuniculi and two underground roads, which probably led from the upper part of the castle to a building below, were also found.
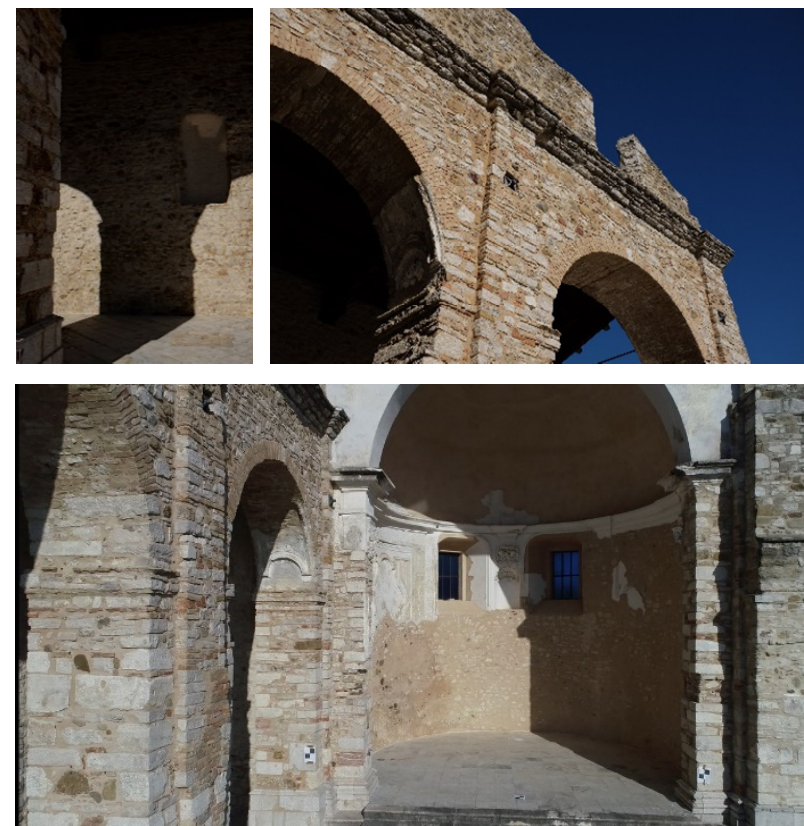

Figure 9: Internal views of the cathedral (R. Marena, October 2019).

Next to this area is the Compsa Amphitheatre, discovered only partially by an excavation campaign in 1997 . Situated next to the gardens, it is in a north-west south-east direction and dates back to between the $1^{\text {st }}$ century B.C. and the $1^{\text {st }}$ century A.D. In the eastern part of the excavation there emerged the wide hemicycle of the amphitheatre, limited behind by the first ring of the gallery of the lower ambulatory and covered by a barrel vault and some radial septa, probably the perimeter walls of the entrances to the bleachers, the vomitoria (Fig.11). The investigation, also, led to the discovery of layering of structures that can be dated back to between the late ancient period and the 17 th and $18^{\text {th }}$ centuries, and which are built directly on the trampling floor of the arena.

Currently, the ruins of the modern city, the archaeological evidence and the few restored buildings (for example the museum and seismological centre), constitute isolated segments in an urban continuum that today appears fragmented (Figs. 12 and 13). The area of the Historical Archaeological Park includes, indeed, the existence of numerous areas in which the excavations of the past have left in sight important archaeological complexes that coexist with the palimpsest of the earthquake (AA.VV. 1982; Mazzoleni, \& Sepe, 2005).
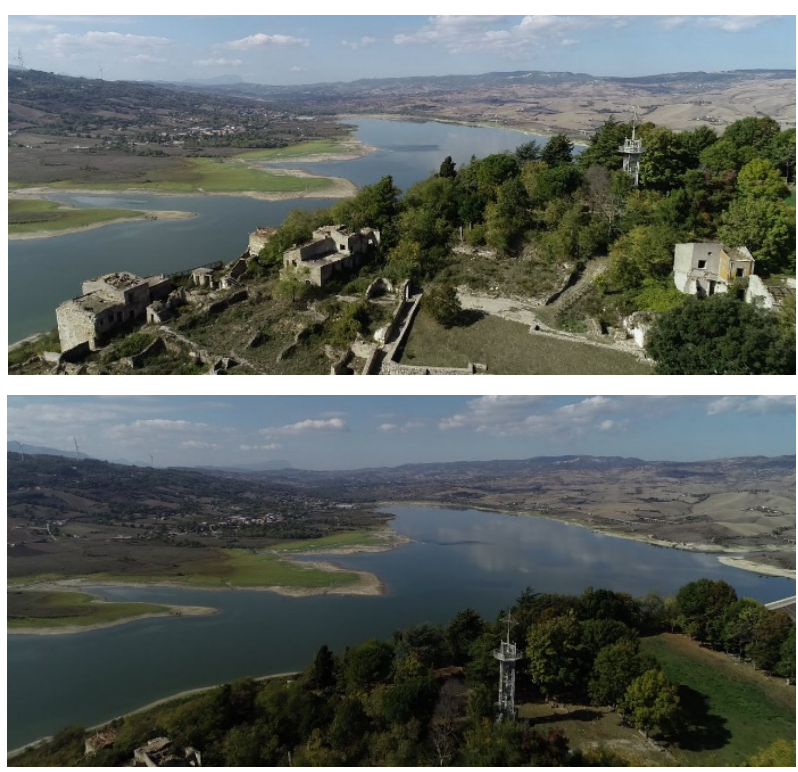

Figure 10: Panoramic views of the garden towards Lake Conza, photogram from a video by the Architect Marco Facchini, October 2019.

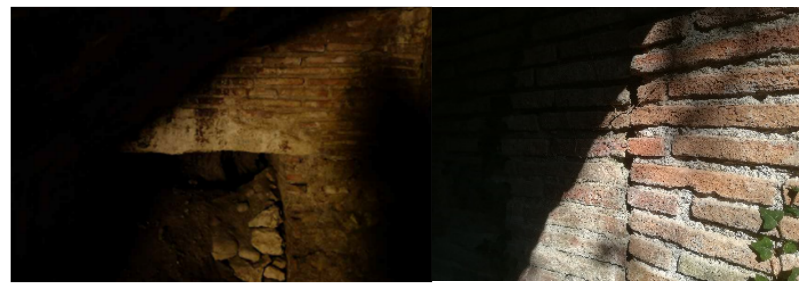

Figure 11: Lower ambulatory of the Amphitheatre. Internal views (R. Marena, October 2019).

\subsection{Continued acquisition of the data for a complex description of the artefact}

The state of the Park's documentation, where the operation was started, was lacking. The archaeological campaigns, over the years, had produced a valid collection of drawings, where only some of them had been digitally produced, but they concentrated on the individual areas of the excavations and on the main archaeological structures, an overall survey was missing.

Along with conducting planimetric surveys of the entire site, detailed forms of the survey were carried out on some technical reference units with the aim of reporting every relevant piece of information as regards the dimensional, material and typological characteristics, and even on the level of the conservation of the structures themselves. It was decided to use forms of technology that allowed us to give a precise and implementable datum when dealing with future projects which in turn could be used for the conservation and restoration projects (Marino et al., 2019; Chiabrando et al., 2019). The former operation sequences took advantage of the aerial photogrammetry and led to the integral survey of the Compsa Hill (Fig. 14 and 15) while the latter involved using, at the same time, the aerial photogrammetry and the Laser scanning 3D technology, and dealt with the area of the Forum and the cathedral (Fig. 16). 

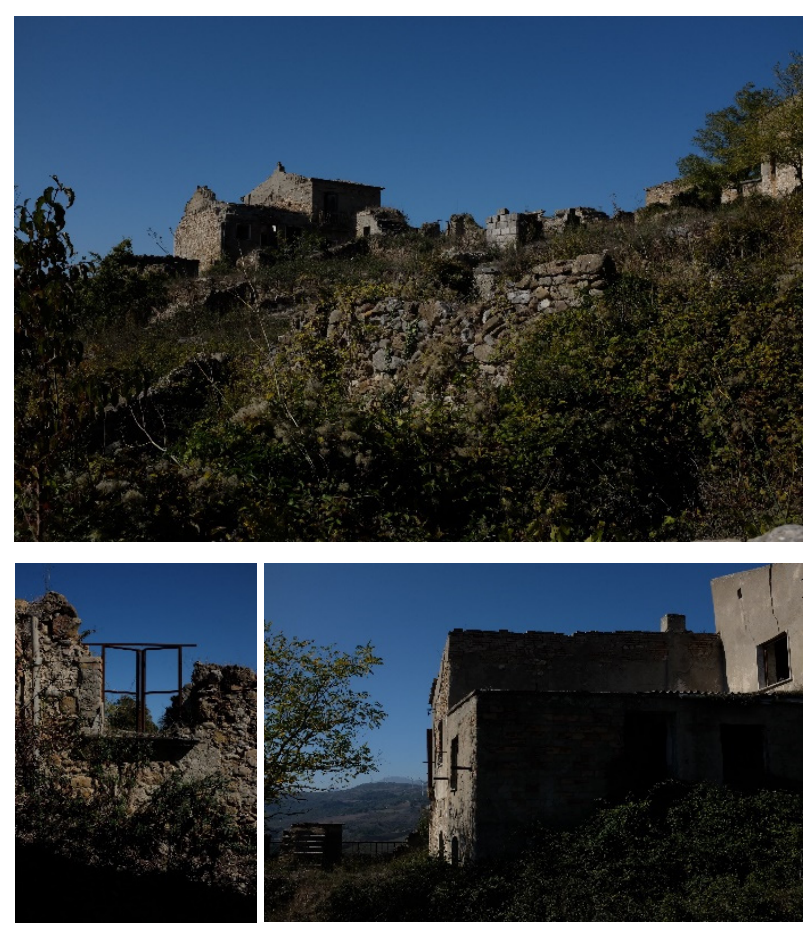

Figure 12: Views of the Manufacturer's house in via S. Michele and the remains of the buildings on the western side of the Buldo Mastroberti house (R. Marena, October 2019).
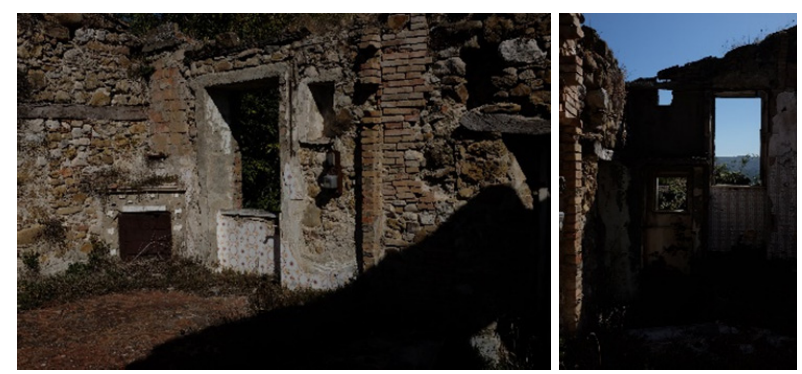

Figure 13: Internal views of the buildings which look out over the square of the Forum (R. Marena, October 2019).

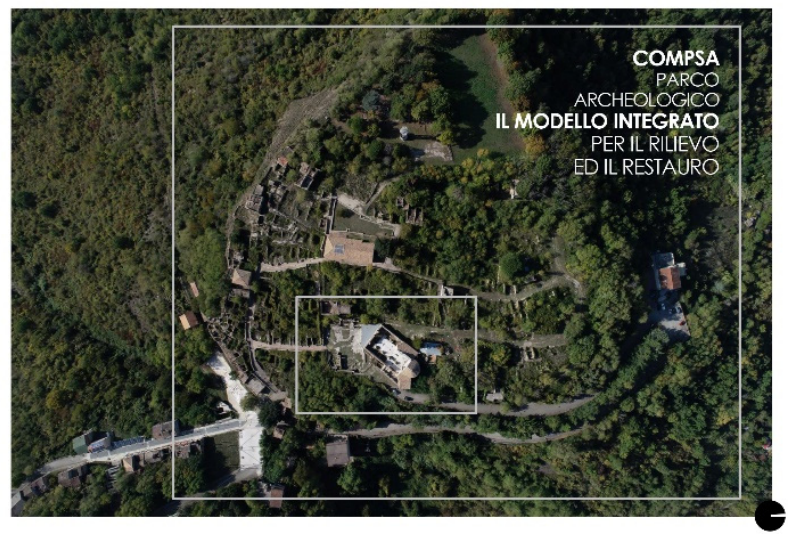

Figure 14: An aerial photo of Compsa Hill by the Architect Marco Facchini, October 2019.

Starting from the orthoprojections of the point clouds which were obtained, a map of the macro-areas relative to the materials and building techniques and the level of degradation associated with them was elaborated on. Besides, it was possible to pick out the articulated transformation of the artefact, which led to conspicuous material integrations (Fig. 17).
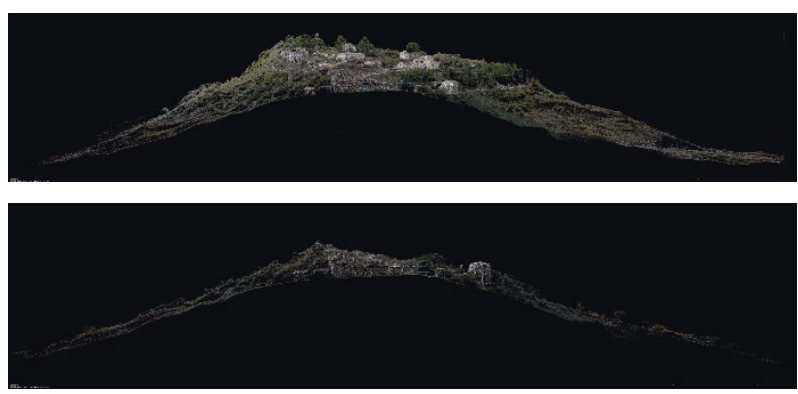

Figure 15: A visualization of the point clouds of Compsa Hill.
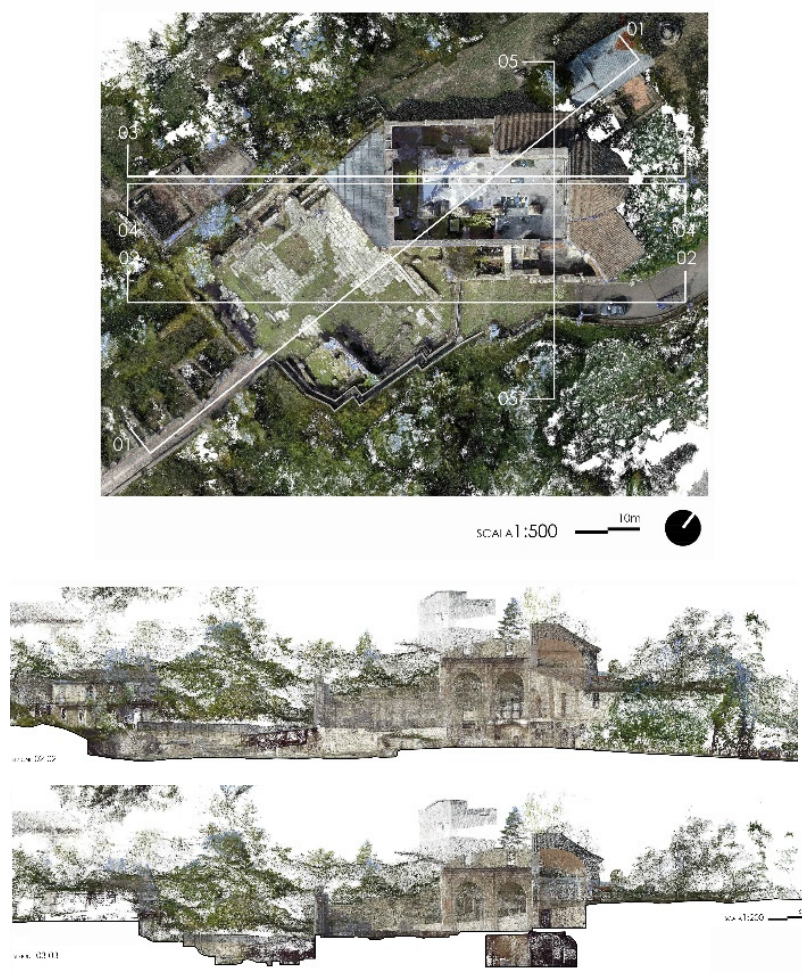

Figure 16: The final drawing of the survey operations carried out in the Historic Archaeological Park in Compsa, October 2019. Map and longitudinal sections along the area of the forum and the cathedral.
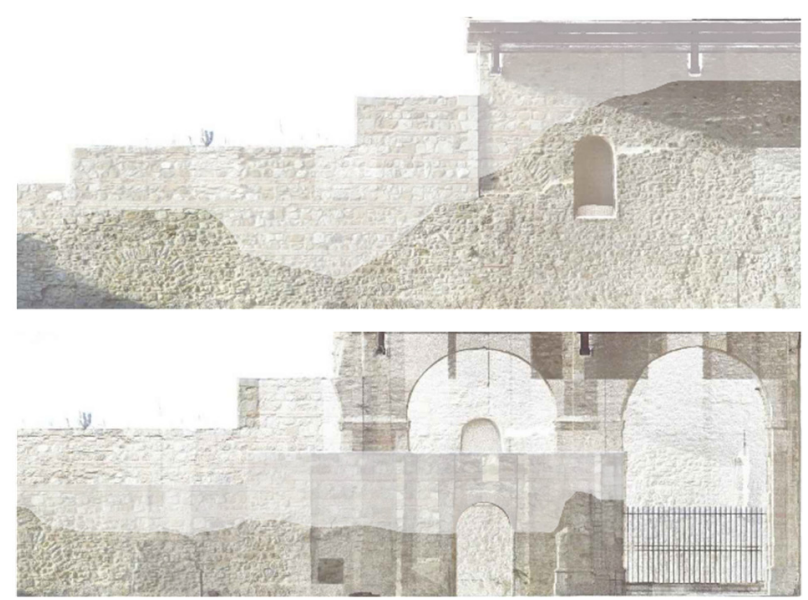

Figure 17: Orthophoto. Masonry details of the left-sided aisle of the cathedral. The re-building interventions are in white (SAABS, 2004-2006) 
The surfaces which were elaborated on, starting from the point clouds allowed us, indeed, to describe not only geometrically and dimensionally the surveyed elements, but also to describe in detail their material consistency. This made the stratifications legible, as well as the degradation of the materials and the lesions. This complied with the need to produce a support model for the restoration and conservation activities (Marino, 2017). This material allowed us to build up a data-base relative to the historical masonry typologies and the variants used during the restoration work which took place afterwards (Fig. 18).
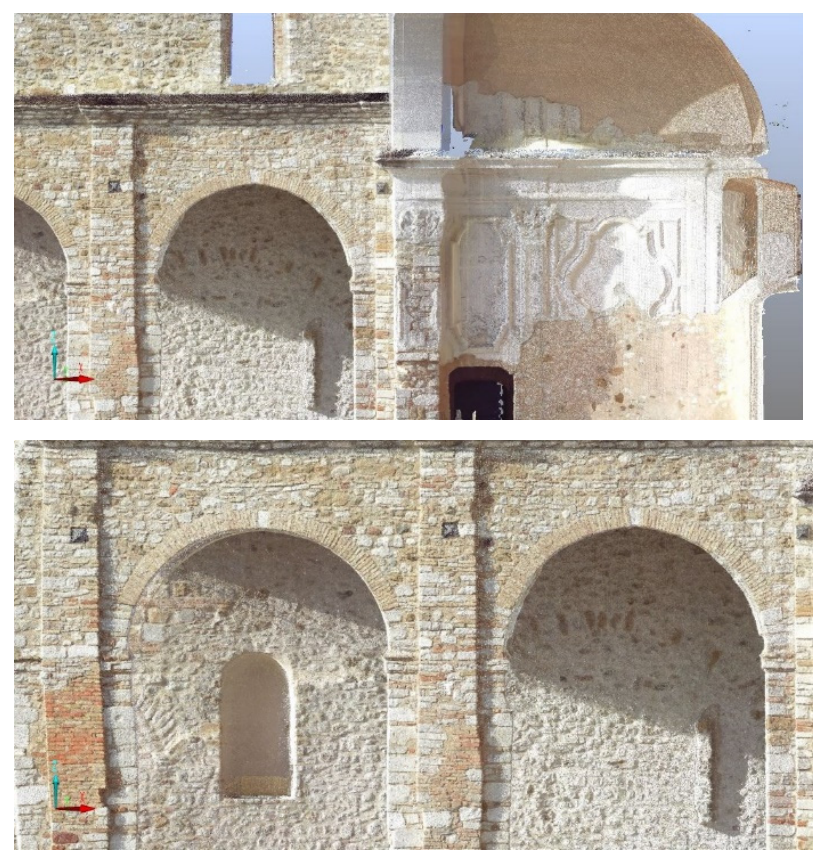

Figure 18: Masonry details of the cathedral. Orthoprojections of the surveyed point clouds.

The survey methodology adopted had double usefulness. On one hand, it allowed to obtain metric forms of survey and accurate graphic representations and on the other, it provided support for an integrated reading which attempted to link the interpretation of the evolutionary dynamics of the site to the material stratifications of the artefact and their level of conservation (Aveta, Marino, \& Amore, 2017).

\section{Instrumentation, data and representation}

The particular orography of the places led to the use of two survey techniques which helped give back the morphometric consistency of the archaeological area. The principal aim of the survey campaign was to build a model through which we could explore the morphology and the relationship between the parts, as well as draw up and elaborate on efficient representations to enrich both the technical and scientific documentation. From the acquisition work, those structure surveys which did not allow us to work in a safe way were excluded. The survey operations were carried out in two phases, the first in November 2018, with the survey of the whole hill and we used the photogrammetry, whereas the second took place in October 2019, and we used an integrated survey with the help of the photogrammetry and the laser scanning 3D technology. This involved the area which included the Forum and the Cathedral.

\subsection{Operative Methodology. Image-based and Range-based}

In the first survey campaign the acquisition through UAV (Unnamed Aerial Vehicle) was carried out. This involved aerial images which were both of a nadir type and various angle-shots of the entire archaeological complex. The resulting dataset was made up of 740 photograms which had been taken by a drone, a DJI Phantom 4 at a height of 95 metres with a $70 \%$ overlapping (overlap and sidelap) and we obtained orthoprojections with a GSD (ground sample distance) of $3.19 \mathrm{~cm} / \mathrm{px}$ (Fig. 19). and this was elaborated on with the help of an Agisoft Photoscan photogrammetric modelling software system. This process allowed us to re-build the current state by creating a three-dimensional model, which was used as a research instrument to create orthographic planes and sections of the site.

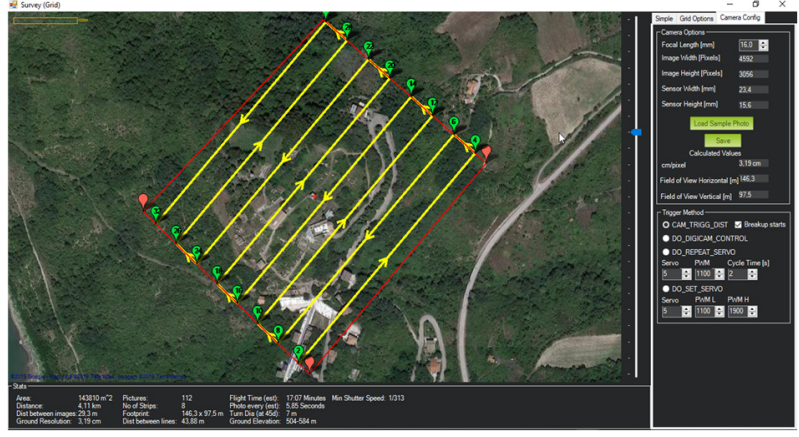

Figure 19: Preliminary flight planning. November 2018.

In the second survey campaign, we continued with the integrated survey of the area which includes the Forum and the Cathedral through the use of the UAV and a scanner laser. The dataset was made up of 366 photograms which were taken by the drone at a height of 33.5 metres with a $70 \%$ overlapping and the orthoprojections were obtained with a $0.85 \mathrm{~cm} / \mathrm{px}$ GSD (Fig. 20).

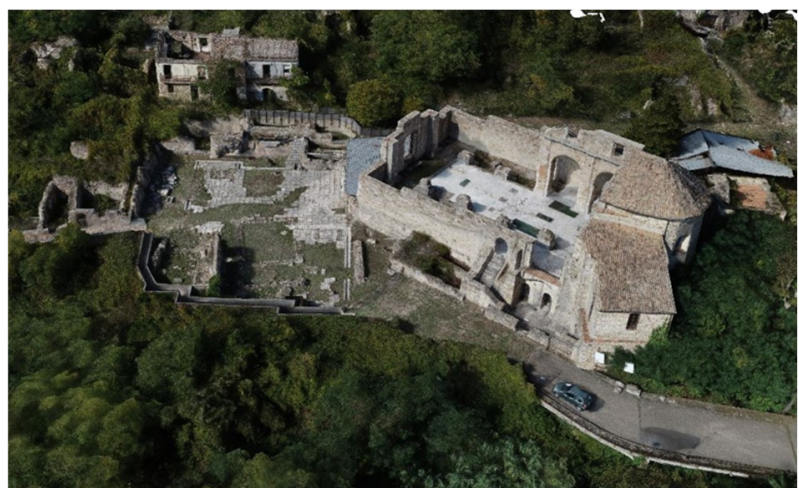

Figure 20: Dense point clouds of the Cathedral and the Forum.

The photographic acquisition made by the UAV needed a preliminary shot project, based on the map of the area in question with the help of Mission Planner. This software allows the creation of flight paths through the creation of waypoints that set out the route, the number of shots, and the value of the ground resolution. The operating and 
environmental factors which could influence the reconstruction so as to ensure the maximum coverage of the zone to be surveyed were taken into account.

Regarding the survey when using the laser instrumentation on the site and acquiring the morphometric characteristics of the Forum and the Church of Assunta, a TLS (Terrestrial Laser Scanner) phase modulated (phase shift) of the CAM2/Faro, the Focus 3D X330 model. This type of instrumentation allowed us to acquire information that was useful in defining the typology of those parts of the complex which could not be reached by any other instrument or survey technique. (Wei, Chin, Majid, \& Setan 2010) For the alignment of the scans, two methods were essentially used, i.e. natural points and artificial targets. With the aim of operating efficiently, particular attention was paid to the positioning of the zoned targets which were necessary to join the point clouds and because of which there was a constant verification for the pairs of consecutive takes.

In reference to the survey of the area of the Forum and the Cathedral of the Assunta, 44 scannings were carried out, choosing appropriate station points which presented to a lesser extent possible occlusion. The resolution was 6.136 millimetres and was measured on a plain 10 metres from the emitter, with a $3 X$ quality, the time used for any scan was 7 minutes (Fig. 21). The clouds which were acquired were alignment through the collimation of the artificial targets while for some of the parts which could not be reached directly the cloud to cloud was used. After pre-processing, was proceeded with the alignment phase of the individual scans by establishing the starting scan and aligning all the others to it, applying the rototranslation matrices between the different internal local systems in order to put them into a global reference.

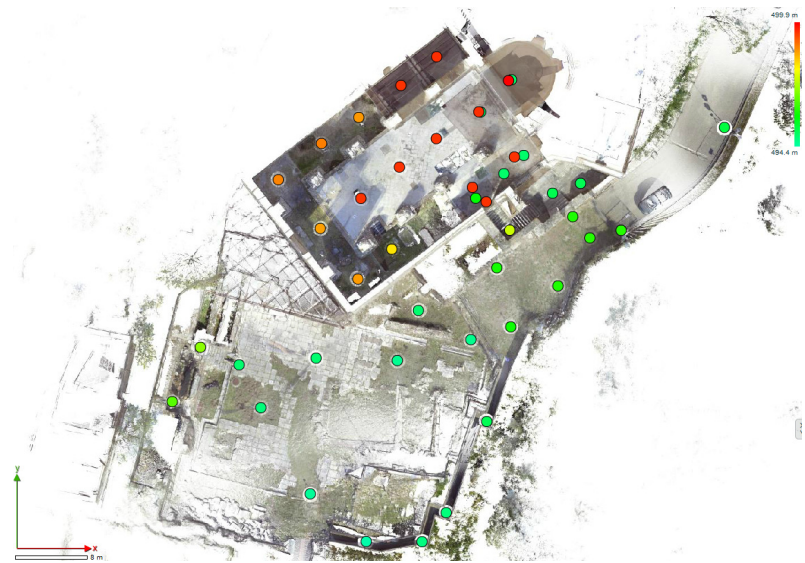

Figure 21: Orthoprojection with the position of the station points of the laser scanner.

This allowed them to be referenced to the reference system through the coordinates in common with the targets, and the successful union of the individual point clouds in a unique three-dimensional model. The data obtained through the laser scanner allowed us to give back dimensional values, generate orthophotos, elaborate on the three-dimensional models, extract textures and produce spherical photos. The choice of technology with active sensors like the laser scanner allowed us to operate also in environments with little lighting like the crypt positioned under the apse of the cathedral, thus giving to it reflectance values. This particular factor allowed us to re-build its geometry.

\subsection{The integrated survey}

With the aim of obtaining a single model from the two point clouds, both in the first and in the second survey campaigns, there were positioned some GCP (Ground Control Points) which materialized through the checkerboard targets and RAD (Ringed automatically detected) targets (Parente, Chandler, \& Dixon 2019). These were visible from the UAV and can be individualized in the point clouds obtained with the help of the laser scanner (Fig. 22). The network of the control points guaranteed the topographical support to alignment both models (the photogrammetric and the laser ones) until the empty spaces present in both the clouds were compensated for. The survey campaigns have, thus, made up an interesting integration application with different forms of technology, whose outcome, in this initial stage of the research-project, can be considered more than successful.

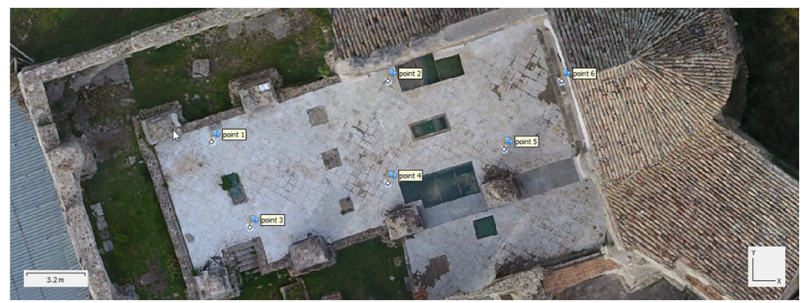

Figure 22: Ground control points materialized with the automatic RAD recognition target. November 2019.

The three-dimensional visualization of the given model proved to be extremely useful for the rapid exploration of the entire complex, allowing us to read the altimetric relationships between the parts and to carry out an initial examination on the three-dimensional configuration of the object (Fig. 23).

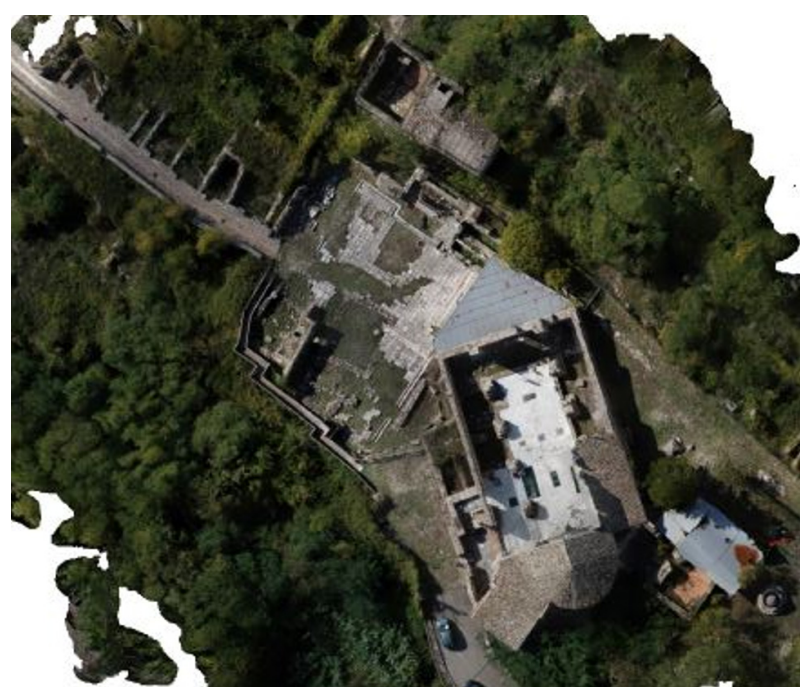

Figure 23: Orthoprojection of the area of the Forum and the Cathedral.

The point clouds allowed us to analyse on various occasions the existing one, operating comparisons and interrogations, also through its on-line fruition. The applicative Scene2Go of the Faro had, in fact, been predisposed on the Apache server.

The configuration of the web server (Faro Scene2Go) allowed us to visualize the data and the virtual fruition of 
the projected space, having archived the various scanning to get access to it from the remote. The system which was used allowed us to interrogate and visit virtually the enjoyable environments through immersive photos (Panoramic Views) and maps (Overview Maps). It is possible to carry out on these products, besides the verification and control procedures, also measurement operations, thus configuring itself as an information archive that can be used for further research-projects. Side-by-side with the traditional orthoprojected representatives, new methods of the visualizing of projected data have been experimented with which can efficiently give back the complexity of the site, such as the articulation and the careful cataloguing of the parameters. Besides, the use of an on-line platform gave us the chance to verify the informative potentialities of the immersive shots, with the aim of singling out new modalities as regards knowledge and fruition.

\section{The dialogue approach for the project and some concluding considerations}

The cognitive field-work of the investigative survey of the above-mentioned survey campaign was carried out by means of numerous on-site visits and choices made in order to deepen, through instrumental recordings, certain aspects of the object of investigation. A rigorous analysis of the conditions and the potential contexts for the re-use and re-launching of the archaeological park at Compsa were also used.

The study of the still existing volumes, their criticalities, the typology and the degree of 'ruin' of the buildings which still allow us to read the layout and the street pattern of the village swept away by the seismic event have contributed to the construction of hypotheses for a likely possibility of sustainable reuse. A wide-ranging mapping of the existing facilities, enabled us to measure its 'pulse' with regard to the attractiveness of the site, while a community survey on the perception of the abandoned site as a place of collective memory provided significant data to support the project proposals (Carbonara, 2017). The perception of the scenery and the physical and immaterial relationships with the new Conza allowed us to hit upon the strategies and destinations to be used, which are both compatible and auspicious. Some basic functions have been provided (a bookshop, a snack bar, and so on) and different 'cultural devices' which could be the start of a widespread, intercounty, developmental process, along with other possibilities. In particular, the Laboratories (visual anthropological ones, an active memory one, a spontaneous theatre, a rural design one, an immaterial patrimony one and a start-up laboratory for the various urban projects) would transform, in the planning forecast, the park into an active and propulsive site. Recuperating the urban-natural pathways, through a planned project, would lead to the fruition of the site and ruins which would be inserted along with the archaeological data of the re-emerged destroyed past, would become the material headquarters for an active memory with regard to its collective re-use.

The 'waiting' behaviour - referred to at the beginning of this contribution - with regard to the process of marking down the data and their processing thus represent one part of the methodological process of the project proposal. The very same thematic representation that relating to materials and construction techniques and degradation, basic steps in the methodology of the restoration project, supported by the indispensable and preliminary historicalcritical study, was therefore enriched with new interpretative in-put. Among these, there are: the flagrancy of the material, the presence of cast-off materials, as well as hypogean parts, the micro-histories impressed on the surfaces of the surviving internal parts, or even the hidden pathways which, back in the day, built up a visual relationship with an urban interior or with the Irpinian scenery or even the individualization of 'archaeologically fertile' areas. These are points that a specific instrumental campaign, through deep, critical reading, could bring to light. The restoration approach has thus revealed a project that is sensitive to what exists, in fruitful interaction with the instrumental survey. This interaction attentive to the preservation of contemporary meanings, with the aim of transformation to enhance them and, finally, the recovery of a social and physical fracture, which even nowadays can be perceived, between the new Conza and the people from Conza with a still painful past (Marino, Rispoli, \& Vitale, 2016; Marino, 2020).

Comparison and dialogue between disciplines, therefore, between "other interpretative grammars" can give rise to proposals and horizons for the life of a building or a site, with an operative approach based on the genius loci and the questions that pre-existence inevitably poses. These are topics that, if grasped in their complexity and seen through different reading filters, can offer appropriate solutions to the multiform values of the heritage.

\section{Acknowledgements}

This work was supported by Prof.ssa Arch. Bianca Gioia Marino, Prof. Arch. Riccardo Florio, Prof. Arch. Raffaele Catuogno, Coll.: Arch. Marco Facchini and explains the results in the thesis study by arch. Rossella Marena. (Department of Architecture, University of Naples Federico II, a.a. 2018-2019).

\section{References}

AA.VV. (1982). Campania oltre il terremoto: verso il recupero dei valori architettonici, Catalogo della mostra "Campania oltre il terremoto", Arte tipografica, Napoli.

Acocella, V. (1927-1928). Storia di Conza, I, Il gastaldato e la contea fino alla caduta della monarchia sveva, estratto dagli "Atti della Società Storica del Sannio", Benevento 1927-1928 F.Barbagallo, Sviluppo e sottosviluppo agli inizi del Novecento, in Id. (a cura di), Storia della Campania.

Aveta, A., Marino, B.G., \& Amore, R. (2017). Materia e realtà storica. Catturare la trasformazione: un approccio transdisciplinare alla conservazione. In 'ANANKH, Numero speciale novembre 2017, 30-36.

Carbonara, G. (2017). II restauro fra conservazione e modificazione. Principi e problemi attuali, artpaparoedizioni, Napoli. 
Chiabrando, F., Marino, B.G., Fissore, F., Lingua, A.M., Masiero, A., \& Vettore, A. (2019). UAV Photogrammetric Model of Girifalco Fortress, in Marino, B.G. (ed.), Across the Stones. Images, landscapes and memory. The interdisciplinary knowledge for the conservation and enhancement of the Girifalco Fortress, Collana frequenze_conservazione/restauro, artstudiopaparo, Roma.

Colucci Pescatori, G. (1988). Conza della Campania, l'Attività Archeologica nelle Province di Salerno, Avellino e Benevento. In Atti del XXVII Convegno di Studi sulla Magna Grecia (Taranto-Paestum, 9-15 ottobre 1987), Taranto.

Di Giovanni, V. (2015). Compsa tra Irpini e Romani, Tesi di dottorato in Storia Romana, Università degli Studi di Napoli "Federico II". Dipartimento di Studi Umanistici, Scuola di Dottorato di Storia (XXVII ciclo), Prof.ssa A. Storchi Marino, Coordinatore Prof.ssa A. M. Rao.

Gargano, G. (1934). Ricerche storiche su Conza antica, Avellino (Ristampa anastatica Calitri 2011).

Johannowsky, W. (1982). Risultati e prospettive della ricerca archeologica irpina, in AA. VV., Conza alla ricerca del passato. Atti dell'incontro- dibattito tenuto a Conza l'11 agosto 1979, Calitri.

Johannowsky, W. (1994). Conza (Compsa), in EAA, II, supplemento, Roma, 262-263.

Marino, B.G., Rispoli, F., \& Vitale, F. (2016). Memorie dalla città a venire. Decostruzione e conservazione, artpaparoedizioni, Napoli.

Marino, B.G. (2017). La complessità della rappresentazione come potenzialità della conservazione,. In 'ANANKH, numero speciale GeoRes novembre 2017, 11-12.

Marino, B.G. (2019). Data Optimization for the 3D Modeling and analysis of a Fortress Architecture. In «Geomatic \& Restoration. Cultural Heritage: challenges, new perspectives and technology innovation. Towards informative content models and beyond» re (Milan, 8th-10th May 2019).

Marino, B.G. (2020). Patrimoni e memorie in dissolvenza: dinamiche di trasformazione e di abbandono dei centri dell'Alta Irpinia tra distruzione e ri-costruzione. In A.M. Oteri, G. Scamardì (a cura di), Un paese ci vuole. Studi e prospettive per i centri abbandonati e in via di spopolamento, «ArcHistor» Extra, 7 (supplemento di «ArcHistoR» 13/2020).

Mazzoleni, D., \& Sepe, M. (2005). Rischio sismico, paesaggio, architettura: Irpinia, contributi per un progetto. Centro Regionale di Competenza Analisi e Monitoraggio del Rischio Ambientale, Università degli Studi di Napoli Federico II - CRdC-AMRA.

Wei, O. C., Chin, C. S., Majid, Z., \& Setan, H. (2010). 3D documentation and preservation of historical monument using terrestrial laser scanning. Geoinformation Science Journal, 10(1), 73-90. http://eprints.utm.my/id/eprint/27787/1/ZulkepliMajid2010_3DDocumentationandPreservationofHistorical.pdf

Rea, R. (1982). Primi risultati della ricognizione archeologica nel territorio di Conza, in AA. VV. Conza alla ricerca del passato. Atti dell'incontro-dibattito tenuto a Conza l'11 agosto 1979, Conza della Campania.

Sgobbo, I. (1938). Ricerche topografiche dell'antica Compsa. In Atti della Reale Accademia Nazionale dei Lincei, Notizie degli Scavi di antichità, vol. XIV, serie VI, Roma.

Parente, L., Chandler, J. H., \& Dixon, N. (2019). Optimising the quality of an SfM-MVS slope monitoring system using fixed cameras. The Photogrammetric Record, 34(168), 408-427. https://doi.org/10.1111/phor.12288.

Veca, S. (2017). Non c'è due senza tre, in Terza Cultura. Idee per un futuro sostenibile. A cura di V. Lingiardi e N. Vassallo. 